\title{
ПРИЧИНЫ ВОЗНИКНОВЕНИЯ ТЕНЕВОЙ ЭКОНОМИКИ
}

\author{
Макаренко Александр Олегович \\ Студент, Кубанский государственный \\ аграрный университет \\ 350044, Россия, Краснодар, улииа Калина 13 \\ Мамий Сима Асламбечевна \\ Кандидат экономических наук, доцент \\ Кубанский государственный \\ аграрный университет \\ 350044, Россия, Краснодар, улица Калинина 13
}

Аннотация. Данная работа посвящена исследованию такой проблемы, как теневой сектор экономики, развитие теневой экономики, а также ее влияние на протекание основных экономических процессов: формирование и распределение дохода, торговлю, инвестирование и экономический роста в целом.

Annotation. This work is devoted to the study of such problems as the shadow sector of the economy, the development of the shadow economy, as well as its impact on the course of the main economic processes: the formation and distribution of income, trade, investment and economic growth in general.

Ключевые слова. Теневая экономика, экономика, экономическая безопастность.

Keywords. Shadow economy, economy, economic security.

Теневая экономика - деятельность людей, осуществляющаяся вне государственного контроля, которая включает в себя подпольное изготовление запрещенной продукции и ее реализации, всевозможные денежные махинации и т.д. [1]

Структурные элементы теневой экономики представлены на рисунке.

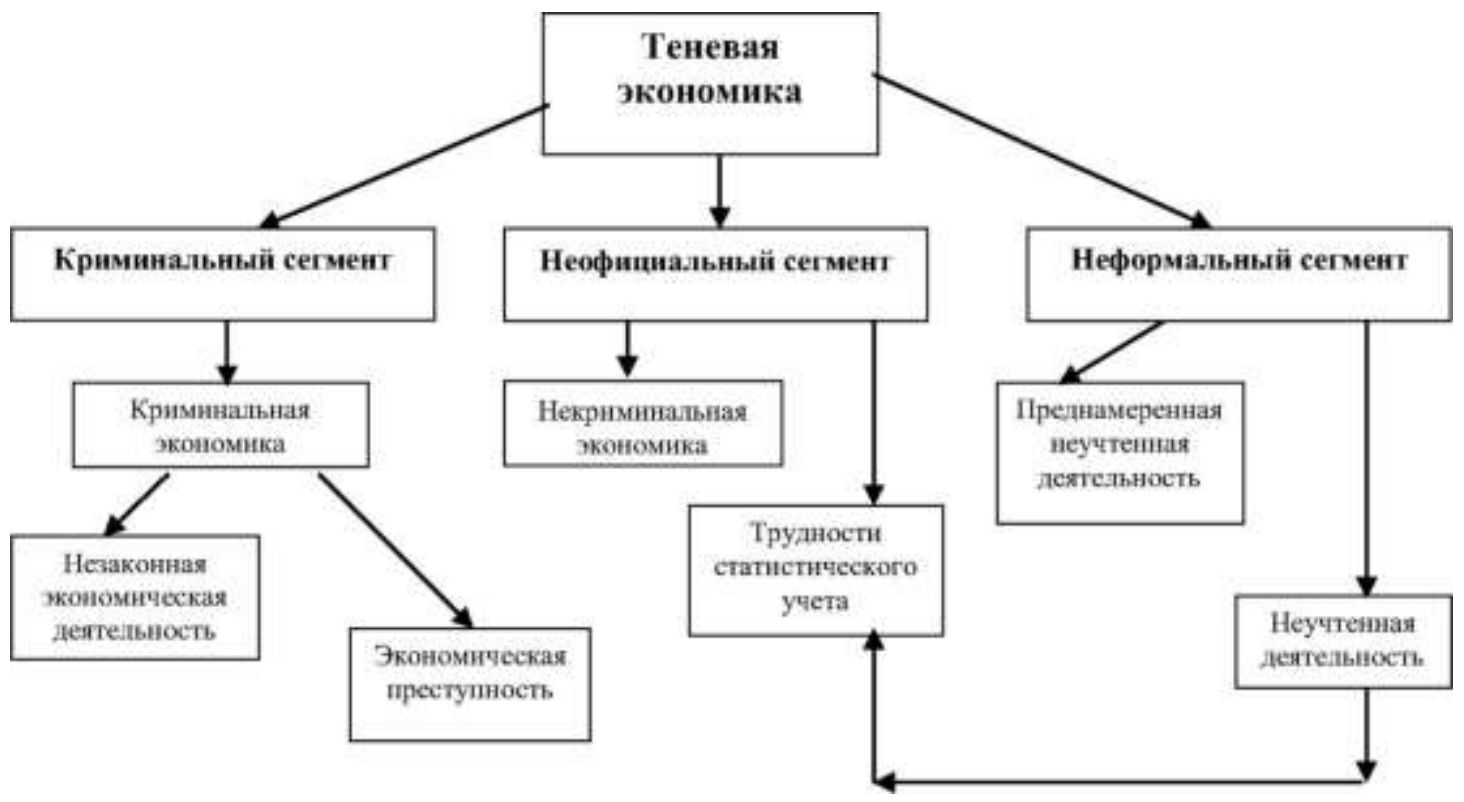

Рисунок 1 - Структура теневой экономики

Понимание понятия «теневая экономика» существенно различается в зависимости от выбранного подхода к исследованию. В таких случаях, в зависимости от выбора того, или другого критерия различаются учетностатистический, криминологический, формально-правовой и комплексный подходы.

Возникновение теневой экономки в началось еще в СССР (конец 60-х - начало 70-х годов) и охватывало такие виды хозяйственной деятельности, которые осуществлялись вне прямого государственного контроля и санкций со стороны официальных органов управления партийных комитетов разного уровня. Теневая деятельность стала элементом социально-экономической системы СССР. В те годы к числу распространенных видов теневой деятельности относились всевозможные бартеры, нечётные выпуски продукции. Постоянный дефицит товаров в стране привел к спекуляции, которая составляла неотъемлемую часть теневого сектора. 
Немаловажной причиной развития теневой деятельности в нашей стране считается значительный рост доходов к низким темпам товарного наполнения потребительского рынка. [2]

Для начала, необходимо выявить этапы формирования теневой экономики в постсоветском пространстве:

- Первый этап охватывает период (1991-1994г.). Ключевым процессом данного этапа явилась массовая приватизация. Гражданам выдавались ваучеры, символизирующие их долю в народном богатстве;

- Второй этап(1995-1996г.). На данный период приходится денежный этап приватизации, проходивший на основе Указа Президента о залоговых аукционах;

- Третий этап (1997-1999г.). Здесь, огромное влияние на формирование теневого сектора оказал финансовый кризис 1998г. Крупные бизнесмены успели спасти и даже приумножить свои средства. [4]

Немаловажным является рассмотрение причин развития теневой экономики:

- Возникновение структурного и экономического кризиса, вследствие которого осложняется ситуация на рынке труда, которая порождает всплески малого предпринимательства и самостоятельной занятости

- Массовая миграция из стран “Третьего мира", дополняемая внутренней миграцией

- Характер государственного вмешательства в экономику.

Доля неформальной экономики зависит от трех составляющих: степени регулятивного вмешательства, уровня налогообложения и масштабов коррупции.

- Открытие внешних рынков и обострение конкурентной борьбы со странами "третьего мира", побуждающие снижать издержки всеми легальными и нелегальными способами. [3]

Так же на становления теневого сектора в нашей стране повлияли 2 вида факторов: сдерживающие и стимулирующие развитие теневых процессов.

Сдерживающие факторы:

- Отсутствие крупных денежных сбережений у населения;

- Ограниченность запросов населения из-за отсутствия информации;

- Жесткое законодательство, практика работы х органов;

- Низкая степень дифференциации населения по уровню материального достатка.

Стимулирующие факторы:

- Рост потребностей вместе с ростом доходов у всех слоев населения;

- Желание населения вкладывать денежные средства, в качестве способа спасения от инфляции.

- Монополизм в экономике.[5]

Помимо представленных факторов, ученые выделяют три группы факторов, способствующих развитию теневого сектора экономики. Данные факторы характерны как для России, так и для других стран:

Экономические факторы.

Социальные факторы.

Низкий уровень жизни населения, что способствует развитию скрытых видов экономической деятельности. Высокий уровень безработицы и ориентация части населения на получение доходов любым способом).

Правовые факторы. Несовершенство законодательства. Недостаточная деятельность правоохранительных структур по пресечению незаконной и криминальной деятельности. Несовершенство механизма координации по борьбе с экономической преступностью.

Также следует выделить государственное вмешательство в экономику как следствие развития и роста теневого сектора. Во-первых, регистрации бизнеса. Во-вторых, нежелание собственников выплачивать налоги государства. Так, в 90 годы, фирмы в качестве налогов должны были выплачивать свыше половины вновь созданной стоимости.

Таким образом, рассмотрев все причины и факторы становления теневой экономики в нашей стране, можно сказать, что каждый фактор сыграл неотъемлемую роль в развитии теневого сегмента. Главной, из всех причин, является развитие спекуляции. Ведь привозя товары нелегально из-за границы, люди уже расшатывали этим экономику своей страны. Незаконная продажа “из под прилавков” давала продавцам неплохой доход. [5]

\section{Литература}

1. Постановление правительства РФ от 15.04.2014 №316 Об утверждении государственной программы Российской Федерации «Экономическое развитие и инновационная экономика» [Электронный ресурс]. - Режим доступа: http://base/garant.ru/70644224/

2. Альпидовская М. Л. Экономические основы теневой экономики и коррупции бюрократического аппарата [Текст] / М. Л. Альпидовская // Менеджмент в России и за рубежом. - 2014. - № 7. - С. 137 - 138.

3. Белкина С. А. Государственное регулирование сокращения теневого сектора в современной России [Электронный ресурс] / С. А. Белкина // Экономика и жизнь. - 2016. - № 5 - 6. - Режим доступа: http://www.dslib.net/econom-teoria/tenevaja-jekonomika-v-strukture-hozjajstvennoj-dejatelnosti-sovremennogorossijskogo.html

4. Латов Ю. В. Теневая экономика. [Электронный ресурс] / Ю. В. Латов. - М.: Юрайт, 2015. - 336 с. Режим доступа: https://institutiones.com/download/books/1861-tenevaya-ekonomika-lagov.html 5 Теневая экономика в 
России: больше вреда или пользы [Электронный ресурс]. - Режим доступа: https://www.bbc.com/russian/features41130228 